La ultraderecha estadounidense en pantalla. Cult

Eva Gómez Fernández

Question/Cuestión, Nro.70, Vol.3, diciembre 2021

ISSN: 1669-6581

URL de la Revista: https://perio.unlp.edu.ar/ojs/index.php/question/

IICom -FPyCS -UNLP

DOI: https//doi.org/10.24215/16696581e628

\title{
La ultraderecha estadounidense en pantalla
}

\section{Cult}

\section{American right-wing extremism on screen}

\section{Cult}

\author{
Eva Gómez Fernández \\ Universidad de Cantabria \\ España \\ evagomezfer22@gmail.com
}

\section{Resumen}

American Horror Story (AHS) es una serie estadounidense de naturaleza antológica que comenzó su andadura televisiva en 2011 y, en la actualidad, su décima temporada está en emisión. En 2017 Ryan Murphy y Brad Falchuk, los creadores, llevaron a la pantalla su séptima entrega, Cult que nos presentó a los círculos ultraderechistas que encumbraron a la victoria electoral al candidato del Partido Republicano, Donald Trump. En estas páginas abordaremos el discurso, así como las referencias que aparecen de dicho espectro ideológico en los episodios que la componen. Así, daremos cuenta de la complejidad que subyace en un 
fenómeno tan poliédrico como lo es el extremismo de derechas y, en este sentido, la precisión que han tenido los arquitectos de la serie para reflejarlo en la cultura popular.

Palabras claves: ultraderecha estadounidense; American Horror Story; Cult; supremacía masculina; vigilantismo.

\section{Abstract}

In 2017 FX aired Cult, the seventh season of American Horror Story (AHS). This American anthology series, which began its run-on television in 2011 and it's still on the air, introduces us in this instalment to the right-wing extremism circles that brought the Republican Party candidate, Donald Trump, to electoral victory. In these pages, we will address the discourse and the references reflected in this ideological spectrum in order to understand its imposition on society. In order to outline our objectives, we will watch the eleven episodes that make up season. Our objectives will show the complexity that underlies such a multifaceted phenomenon and, in this sense, the precision that the creators of the series have had in reflecting it in popular culture.

Key Words: American right-wing extremism; American Horror Story; Cult; male supremacy; vigilantism.

\section{Introducción}

En estas páginas disertaremos sobre las nociones políticas de Cult la séptima temporada de American Horror Story que abordó a los diversos colectivos ultraderechistas que votaron en los comicios estadounidenses de 2016 al candidato del Partido Republicano, Donald Trump. En ese sentido, Xavier Peytibi y Sergio Pérez-Diáñez (2020) han apuntado que, aunque el mandatario Trump integrase su mensaje populista dentro de la derecha alternativa, a partir de ahora alt-right, esto no implicaba que fuera partidario de esa ideología o que se identificase con las diversas tendencias que la componen. Hemos empleado como título del presente artículo "la ultraderecha estadounidense" porque, en sí mismo, es un término global que aglutina a todos los sectores extremistas de derechas que, pese a tener puntos en común porque parten de un mismo corpus doctrinal, difieren entre sí ya sea por cuestiones religiosas, raciales o culturales. Es por ello que dada la proliferación de las diversas corrientes que 
aparecen en la temporada que examinaremos; supremacistas blancos, confederados, nacionalsocialistas, aceleracionistas o trumpistas, entre otras, daremos uso a ese rótulo a lo largo de nuestro escrito. No obstante, también usaremos el rótulo "extrema derecha", pues de acuerdo con Mudde (2020) esta se distingue de otras variantes por el uso sistematizado de la violencia $\mathrm{y}$, en este caso, se exhorta a ella. Además, el caso que aquí nos atañe usa diversos componentes de las extremas derechas, por tanto, es complejo determinar en qué variante se encuadra Kai Anderson, el personaje que examinaremos.

Nosotras nos centraremos en los elementos con los que Kai Anderson, el líder de la organización que analizaremos, vertebró su discurso radical, así como también en su capacidad discursiva para movilizar a la ciudadanía que sentía desafección hacia el sistema democrático vigente y hacia los políticos. En este marco, es necesario comprender que Anderson devino icono de ese grupúsculo porque sintetizó los puntos ideológicos que compartían sus simpatizantes; la masculinidad tóxica y la milicia como bastión contra el mundo moderno. En tal sentido, creemos pertinente destacar que adoptó componentes de la derecha nacional populista, tanto europea, como estadounidense, para utilizar estrategias de manipulación y para emitir mensajes que calaron en sectores interclasistas que buscaban respuestas simples a problemas complejos que están presentes en las coyunturas sociopolíticas del momento y que, además, se asocian a la inmigración, a crisis económica y a la quiebra del Estado providencial (Eatwell y Goodwin, 2019).

La metodología que hemos usado para examinar nuestros objetivos será el visionado de los once episodios que componen esta temporada pues, los productos audiovisuales, tal y como determinó Marc Ferro (1977:15-30), nos pueden ayudar a elaborar un "contraanálisis de la sociedad" porque, al igual que los contenidos posteados en plataformas digitales, pueden constituir un testimonio histórico. Sabemos, por otro lado, que las producciones televisivas pueden estar sesgadas ideológicamente, pero nuestra misión como científicas sociales es realizar una exégesis de los símbolos que se proyectan. Así, nos apoyaremos en la bibliografía académica especializada en este tema, así como también en fuentes secundarias de la hemeroteca para trazar con la mayor exactitud posible nuestro sujeto de estudio.

Dicho esto, nos focalizaremos en dos temas. El primero, el culto que se erigió en torno a la masculinidad tóxica como símbolo opresor, en tanto que elemento patriarcal. El segundo, 
la creación de milicias entendidas como la expresión máxima de la libertad. Con estos aspectos resueltos, también haremos hincapié en la importancia que tienen las redes sociales para la emisión y configuración de los discursos del odio. Ahora bien, antes de adentrarnos en la temática en cuestión es necesario hacer una puntualización que es bastante llamativa. En la Europa de entreguerras, la experiencia nazi-fascista seguía viva en el imaginario colectivo de los países, por lo que, las formaciones de ese signo ideológico no se denominaron ni neonazi ni neofascista y, además, adoptaron las tesis de la diversidad cultural en detrimento del racismo biologicista que había caracterizado al nacional-socialismo (Sanromán, 2008:212-221). Sin embargo, en Estados Unidos el contexto era diferente: en su territorio no se había desarrollado la segunda contienda mundial y, por tanto, hubo organizaciones pro-nazis que mostraron su apoyo al Tercer Reich hasta que, en 1959, George Lincoln Rockwell fundó el Partido Nazi Estadounidense (PNE) que sigue en activo. Esto, que sería disparato en otra región, tiene una explicación. Desde 1876, momento en el que concluyó el periodo conocido como Restauración, hasta 1965 se decretaron las leyes de Jim Crow que segregaron racialmente a los ciudadanos y, durante el régimen nazi, ese modelo de estratificación racial se implantó en Alemania (Chips y Lyon, 2000: 25-28). Cuando las potencias del Eje cayeron, los métodos de hostigamiento nazi, por otra parte, se plasmaron en el programa político del PNE que demandaba la necesidad de instaurar cámaras de gas para que se erradicara de la faz de la tierra a los "traidores" estos eran los judíos, las personas racializadas y los liberales (FBI, 1965:18). A colación con ello, el personaje de Jack Samuels era proclive al nacional-socialismo y, además, tenía objetos con iconografía nazi.

A su vez, hay aspectos que parecen incongruentes en los idearios de esta facción política. Hay varios personajes homosexuales que, atraídos por las dotes oratorias de Kai, se integraron en el grupo. Esto, que resultaría irrisorio en otro momento histórico, porque los activistas de la comunidad LGBIT+ fueron perseguidos por ultraderechistas. Sin embargo, muchos dirigentes de la alt-right son homosexuales, pero rechazan taxativamente la categoría de "gay" porque se autodefinen como andrófilos que es un término que acuñó Jack Donovan en 2006 cuando publicó Androphilia: Manifiesto Rejecting the Gay Identity, Reclaiming Masculinity donde destacó que los homosexuales de estas asociaciones se sentían atraídos por hombres viriles y poco afeminados (Marantz, 2020: 357-361). Hay que comprender que las extremas derechas se han modernizado con el paso del tiempo y, aunque haya ramas homófobas como 
el Ku Klux Klan (KKK), muchos consideran que la condición sexual no determina su activismo político (Mahdawi, 2017).

También se destacaron las pugnas existentes entre los distintos sectores del republicanismo estadounidense pues, en este caso concreto, nos encontramos con Sally Keffler, cuyos padres eran reaganistas, que se postuló como candidata al congreso por el Partido Republicano y se enfrentó públicamente a Kai Anderson a quien tildó de reaccionario por fomentar el odio, el caos y la destrucción. Nosotras consideramos que el político tenía unos intereses, más que reaccionarios, aceleracionistas poco desarrollados, esto es, una nueva tipología terrorista que, situándose en los parámetros de la extrema derecha, está conectada con perfiles solitarios que buscan lazos afines en las diversas plataformas digitales para subvertir los valores modernos y así construir un nuevo mundo (Arias Gil, 2021:18). Por eso, en el primer episodio, Anderson exclamó al conocer el escrutinio final de los votos, Fuck you world ${ }^{(1)}$.

Finalmente, hay que comprender la finalidad que tiene este proyecto audiovisual. Ryan Murphy y Brad Falchuk, los creadores de la serie, han destacado siempre por sus posturas de izquierdas, pero esto no implica que no hagan una crítica a las ramificaciones más radicales de la izquierda posmoderna. Teniendo esto claro, hay que dejar constancia de que el pensamiento de Anderson cambió. Él cursó estudios de género y su rasgo identitario era el cabello tintado de azul que es un símbolo que se relaciona con los aliados feministas. Sin embargo, no le representaba el Partido Demócrata y buscó respuestas alternativas en Internet. En el mundo virtual reina la "Ley del Algoritmo" que, en términos generales, analiza las búsquedas que se han realizado para redirigir al cibernauta a otras páginas donde haya un contenido similar, o más radical, que el que se ha consultado. Las personas que se acercaron a él lo hicieron porque necesitaban a un líder magnético, fuerte y vehemente. La búsqueda de una figura que desempeñe una misión cuasi-proselitista está relacionado con el gregarismo de la masa, tal y como apuntó en 1895 el politólogo Gustave Le Bon en "Psicología de las Masas" donde recogió que el pueblo se guiaba por las emociones en lugar de por el raciocinio y, por tanto, era fácil de manipular. La habilidad principal de este personaje era atraer a izquierdistas que se habían dejado influenciar por la Cultura del Miedo. Vemos que Ally Mayfair-Richards, la antítesis del concejal, a pesar de haber votado a la ecologista Jill Stein que se presentó por el Partido 
Verde, tenía una percepción irracional del miedo, mientras que su esposa Ivy, votante de Hilary Clinton, se unió al grupo de Kai. Cult nos apercibe, en este sentido, de la hipocresía de muchos progresistas que predican un discurso basado en la tolerancia, en el diálogo y en la lucha de clases, pero son los primeros que fortifican sus residencias cuando las tasas de crímenes incrementan y son los primeros que no tienen una conciencia de clase porque no provienen de ambientes precarizados.

\section{Mandwich $^{(2)}$ como reacción a la democracia liberal}

En la década de los noventa eclosionaron células misóginas y antifeministas que se vertebraron en torno a los escritos de Warren Farrell, que escribió El poder masculino, y de Neil Lyndon, que redactó No más guerra de sexos: los fallos del feminismo, que denunciaban la emancipación de las mujeres, el auge de la igualdad y defendían que los gobiernos liberales habían permitido la perversión de Occidente, la filtración de la multiculturalidad y la marginalización de los hombres blancos heterosexuales (Nagle, 2018: 132). En ese sentido, consideraban que el feminismo era un movimiento social que se desviaba del orden tradicional porque atentaba contra la familia, entendida como la célula central sobre la que se erigía la sociedad (Pollard, 2016: 408-412). Ya, en los años setenta, los políticos conservadores y los círculos neonazis habían criticado las obras de feministas radicales que habían influido a una generación de mujeres que consideraba que el matrimonio heterosexual y, consecuentemente, la familia, eran los dos elementos que más habían oprimido al sexo femenino (Nagle, 2018: 126). Kai Anderson tenía como misión restaurar el orden tradicional y subvertir los roles de género y, para conseguirlo, comenzó su andadura política en el ámbito municipal porque, de un lado, la comunidad es el espacio donde se gesta la vida tradicional $y$, de otro, porque el localismo es la representación política de una administración descentralizada. En ese entramado ideológico los hombres son los que deben efectuar la acción política, mientras que las mujeres deben quedarse confinadas en el ámbito privado para cuidar de su progenie y para atender a sus esposos. Eso forma parte del arquetipo tradicional de la feminidad que recibe el nombre de "Ángel del Hogar". Enlazado con esto, consideraba que las obligaciones a las que se tenían que limitar las mujeres eran culinarias porque debían prepararle la cena.

Esta representación de la hegemonía masculina se desenvolvió, a inicios de los dos mil, en foros de internet, así como en redes sociales entre las que cabe destacar 4chan, 8chan 
(posteriormente 8kun), Gab, Facebook, herramienta de referencia de Anderson, o Reddit. Los misóginos, antifeministas y ultraderechistas que convergen en estas plataformas forman parte del espacio que se conoce como "machosfera" donde se intercambian mensajes que apelan a la violencia, las humillaciones y las vejaciones contra las mujeres. Los tres sectores que predominan en esas subculturas son los Incel ${ }^{(3)}$, Men Going Their Own Way (MGTOW) ${ }^{(4)}$ y Pick Up Artist ${ }^{(5)}$ que han creado una mitología en torno a la paradoja de la Pastilla Roja (Minna Stern, 2019:17). Esta es una alusión cinematográfica que se hace al universo de Matrix en el que la píldora roja representa la verdad que el gobierno quiere ocultar a los ciudadanos, es decir, esto se asociaría con la teoría conspirativa del Estado Profundo que afirma que hay una administración en las sombras que aspira a dominar el mundo (FBI, 2019: 4-14), mientras que el comprimido azul permite seguir viviendo en la ignorancia. Kai Anderson se acercó a las teorías de conspiración y, por consiguiente, al radicalismo de derechas, a través del subforo de Reddit, "The Red Pill" donde, a parte de gozar de anonimato y de no haber ningún tipo de control, se desmontó El Relato, esto es, la historia y la narración oficial de los hechos que, supuestamente, han impuesto los gobiernos y los medios de comunicación (Marantz, 2020: 15). Esa alegoría, que se vincula con el nativismo, entronca con el nacionalismo blanco y configura un enemigo, tanto exógeno como endógeno, dicho con otras palabras, las políticas liberales, el feminismo y la multiculturalidad que derivaría de la inmigración musulmana, así como de la hispana (Minna Stern, 2019:7-15). Anderson personificaría al prototipo de líder que representa la idealización de la virilidad, la dominación sexual y la jerarquización masculina. A este respecto, la violencia sexual es una constante. Samuels era homosexual, pero se forzaba a mantener relaciones sexuales con mujeres y, ante la posibilidad de llevar a cabo el acto, agarraba fuertemente el cuello de su pareja sexual para excitarse. Este acto tan macabro lo difundió en redes sociales el periodista Mike Cernovich que, actualmente es uno de los referentes de la alt-right (Marantz, 2020: 230).

Este planteamiento se yuxtapone con el ultranacionalismo, el populismo, la xenofobia, el racismo, el nativismo y el proteccionismo. Este último no suele estar presente en todos los grupúsculos de extrema derecha porque muchas formaciones políticas son neoliberales, pero en este caso la iniciativa económica que propulsa Anderson es el proteccionismo para revitalizar el comercio local. De hecho, uno de sus secuaces, Gary Longstreet, conocido por su filiación trumpista pues portaba una gorra con las iniciales MAGA, acrónimo del eslogan "Make 
America Great Again" que ensalzó Trump durante su campaña electoral, regentaba una tienda de comestibles. Teniendo en cuenta esto, el nativismo, que es la ideología que defiende que los nativos son los que deben tener los privilegios y gozar del Estado de bienestar, impulsa la consigna de la prioridad nacional (Wang, 2021: 23-27). Esta premisa también la contempló Cas Mudde (2007: 123-126) al apuntar que los dirigentes de estos colectivos entendían que la economía nacional debía estar al servicio de los autóctonos y, por tanto, debían configurar una alternativa mixta que se amoldase al proteccionismo.

Enlazado con el nativismo, no podemos obviar que en los portales digitales que frecuentaba el joven aceleracionista, Facebook, Reddit y 4chan, fundamentalmente, aparecían teorías conspirativas antiinmigración. El racismo es un rasgo endémico en la sociedad estadounidense, desde el siglo XIX, pues, no solo hubo sentimientos pro-esclavistas que abanderaron organizaciones supremacistas como el Ku Klux Klan que, para articular su discurso lleno de odio, cuando se abolió la esclavitud, no perdieron la oportunidad de acusar a los ciudadanos negros de conseguir trabajos remunerados, mientras muchos blancos, pertenecientes a las clases sociales más desfavorecidos, pasaban penurias. Lo mismo ocurrió con los inmigrantes asiáticos, mayormente, chinos que se asentaron en la costa de California a mediados del siglo XIX durante la "fiebre del oro" que sufrieron la estigmatización social y ataques violentos 0 , finalmente, la persecución que recibieron los inmigrantes irlandeses por ser católicos dado que, los protestantes que se habían instalado en el territorio abrazaron un israelismo británico que defendía que los anglosajones era el pueblo elegido de Dios (Chip y Lyons, 2000:121). En este caso, vemos que Anderson, cuando se presentó como candidato a la alcaldía, basaba sus argumentos en noticias falsas que encontraba en Facebook, y que no contrastaba con otros datos, que criminalizaban a los latinos, concretamente, a los mexicanos y apoyaba la construcción del muro de México para controlar la inmigración de ese país, tal y como propuso el mandatario republicano (Rodgers y Bailey, 2020). Ese relato enuncia la teoría conspirativa del "gran reemplazo" (6) que, en el país norteamericano se conoce como "invasión Hispana", se divulgó en 8chan cuando un usuario anónimo posteó un manifiesto poco antes de acabar con la vida de veintidós personas en El Paso, Texas (Kenton, 2019). Según esta, la ciudadanía blanca y protestante se iría erradicando con la llegada de inmigración. Para demostrar que los migrantes latinos eran unos criminales, Anderson se acercó a una obra donde trabajaban ciudadanos procedentes de América Latina para cantarlos "la cucaracha", 
canción que se popularizó durante la Revolución Mexicana, mientras les arrojaba un profiláctico que contenía su orina. Estos, en un arranque de ira, cargaron contra él, pero una pareja que comulgaba con sus ideales captó las imágenes, convenientemente, de la paliza que se hicieron virales.

Finalmente, el cabecilla de esa organización había impuesto una suerte de democracia directa que, a efectos prácticos, emulaba el estilo de participación representativa ateniense con el objeto asegurar el ideal de que era el pueblo el que velaba por sus propios intereses y no la élite partidista que, consecuentemente, era la que ostentaba el poder (Eatwell y Goodwin, 2019). Ese esquema dicotómico pueblo/élite forma parte de la hegemonía propuesta por Antonio Gramsci que adoptó la Nueva Derecha Francesa, una escuela de pensamiento que modernizó las bases de la extrema derecha en los años sesenta, cuando incorporó la lucha de clases en un momento en el que la fase del proletariado marxista estaba experimentando un proceso de deconstrucción (Yves-Camus y Lebourg, 2020:126). Esta práctica política no implica que el sistema fuera democrático sensu stricto porque el joven político pretendía instaurar una democracia iliberal que restringiera la pluralidad, los movimientos socio-políticos y los derechos civiles (Mudde, 2020).

\section{El movimiento de milicias como exponente del antifederalismo}

Cuando Anderson irrumpió, democráticamente, en el ayuntamiento, se rodeó de un grupo armado de hombres blancos, atléticos que buscaban reinstaurar los valores tradicionales, y, poco a poco, impuso su voluntad con respecto al del resto de los concejales. Ese cuerpo de autodefensa funcionaba, según consideramos, como una fuerza de choque vigilantista antifederal, antisistema y violenta. La proliferación de estas unidades tuvo lugar hace un decenio, pero su génesis se enmarca en los años ochenta con la difusión del género literario conocido como survivalismo que presentaba un futuro apocalíptico donde, el enemigo internacional del momento, a saber, la Unión Soviética, ejercería un dominio absoluto sobre los países Occidentales (Guerras posmodernas, 2019). En Cult esa amenaza adoptó la forma de la inmigración, la élite liberal y el feminismo. Esa categoría literaria no puede disociarse de la década de los ochenta porque en aquel momento las áreas rurales sufrieron las consecuencias de la crisis económica agrícola, conocida también como la crisis de los granjeros, que promovió el desplazamiento de muchas familias a las periferias urbanas. Los ciudadanos que 
permanecieron en sus propiedades tuvieron que afrontar muchas dificultades; desde problemas con el alcohol y suicidios, hasta violencia intrafamiliar. Simultáneamente, con las conquistas sociales que habían conseguido, tanto las feministas como el movimiento LGBTIQ+, se produjo una crisis de la masculinidad porque se cuestionaron los valores tradicionales (Mulloy, 2008:6). Por tanto, cuando resurgió hace diez años este fenómeno, que representaba al ciudadano blanco de clase media, emergió con una naturaleza localista. Ese rasgo evoca al antifederalismo porque, entre otras cosas, se posicionaron en contra de que un órgano central, este es, el poder ejecutivo, determinase las decisiones políticas y financieras del resto de los estados.

Estas patrullas violentas no son, a excepción del movimiento de los Boogaloo Boys, III\%ers o Patriots Payers (Allchorn, 2021: 10-16) antigubernamentales, pero están a favor de levantarse en armas contra el gobierno si este se corrompe, es decir, si viola la Constitución (Thomas, 2021:34-35) o la Segunda Enmienda que protege el derecho a portar armas. Por ello, cuando Trump barajó la posibilidad de controlar la circulación de estos artefactos muchos votantes le retiraron su apoyo (McKelvey, 2019). En este sentido, uno de los motivos por los que los colonos americanos se rebelaron contra el yugo británico en el siglo XVIII fue porque la metrópoli quería controlar la emisión de armas y limitar su uso (Cornell, 2016: 12-30). Estos cuerpos violentos, por tanto, están vinculados con el localismo y con el orden comunitario. En Cult vemos que los subalternos de Anderson como Harrison Winton que tenían arsenales en sus propios sótanos.

La cultura de las armas en Estados Unidos se imbrica con los republicanos más radicales y con los confederados porque durante la Reconstrucción, periodo que tuvo lugar después de la abolición de la esclavitud y antes de la institucionalización del apartheid, surgió la figura del Minutment o "vigilante" que cometía atropellos contra la población negra, contra la inmigración latina y contra los católicos europeos (Chip y Lyons, 2000:26). Este icono rural, que intentó imitar esa milicia, se romantizó porque adoptó la imagen de orden y de paz, aunque la realidad distaba mucho de ese escenario tan utópico pues, no solo eran ignorantes y violentos, sino también corruptos. Los adeptos de Anderson que pretendían acabar con esa supuesta invasión mexicana a la que aludimos previamente, se organizaron en torno a tres pautas identitarias; la supremacía masculina, el compañerismo combativo y el patriotismo. Sus 
prácticas nos recuerdan a las de los Proud Boys o "chicos orgullosos", que pertenecen a la subcultura de Men Going Their Own Way, porque una de las pautas que debían cumplir a modo de rito de iniciación era abandonar el onanismo (Alptraum, 2019).

Nosotras consideramos que este comunitarismo está relacionado con la tesis que expuso Nancy Isenberg (2017) para puntualizar que sigue imperando el mismo sistema social británico que impide la movilización social contra el que se rebelaron los colonos americanos, en una nación donde la clase media está cada vez más diluida.

\section{Estrategias comunicativas: el mundo virtual y la música}

Hemos apuntado en varias ocasiones la importancia que tiene Internet en el desarrollo del pensamiento ideológico en el que se enmarcan las asociaciones de esta familia política porque el mundo digital ha cambiado la forma de generar y producir contenido. Las redes sociales, al contrario que los medios de prensa tradicionales, son gratuitas, inmediatas, no presentan filtros y son anónimos. Anderson accedió a estos foros de forma anónima para postear sus disparatas ocurrencias, tal y como ha hecho el colectivo Q-Anon, contracción de QAnonymous, que se formó con la confluencia de teorías conspirativas, porque los usuarios que comentaban algo tenían por nombre en su alias del perfil, anonymous. Al contrario que la maquinaria propagandística convencional, los internautas de los foros pueden autoproducir contenido que más tarde adoptan los partidos políticos. Una de las muestras que mejor lo ejemplifica es la rana Pepe que está asociada al supremacismo blanco (Peytibi y Pérez-Diáñez, 2020). Sus aportaciones en la esfera virtual suelen ser memes humorísticos con los que vejan a las mujeres, a las minorías sexuales y a los inmigrantes.

La otra herramienta de captación que aparece para difundir el mensaje es la música. Esa expresión artística ha estado ligada a las agrupaciones políticas, tanto de derechas, como de izquierdas desde el siglo XX, pero se usó como una herramienta de la ultraderecha cuando, a finales de los años sesenta, el movimiento skinhead desarrolló el género rock anticomunista. Este estilo, aunque sigue vinculado en cierta forma a los grupúsculos de signo identitario que han surgido en la última década, con el surgimiento de la alt-right se ha trasladado por el Fashwave que mezcla sonidos electrónicos con colores pastel, luces de neón, estatuas clásicas y frases o discursos de dictadores asociados a la extrema derecha. Han surgido, a su 
vez, derivados como el Cathwave de corte ultracatólico o el Trumpwave que selecciona fragmentos de Donald Trump (Jäger et ali, 2021: 5-14). Anderson visualizó el vídeo viral de una reportera que arremetió contra un joven porque reprodujo en tono satírico grab'em by the pussy ${ }^{(6)}$ que fue una expresión misógina que había enunciado Trump en 2005 (Lilley, 2015). Hay que tener en cuenta que el estilo sonoro crea la pertenencia a un grupo y configura una identidad cultural. El episodio comentado no fue aislado. Ivy conoció a Gary antes de ingresar en el círculo de Kai. Ambos coincidieron una semana antes de las elecciones, comenzaron a discutir acaloradamente hasta que él, para mostrar su virilidad frente a una mujer lesbiana, le agarró con fuerza sus genitales mientras exclamaba esa fase.

\section{Conclusiones}

En estas páginas hemos escrito sobre la representación de la ultraderecha estadounidense en la pantalla y, dada la maestría con la que se ha plasmado en la séptima temporada de American Horror Story bautizada como Cult, hemos comprobado la naturaleza poliédrica de ese fenómeno, por lo que es complejo encuadrar a Kai Anderson en una corriente determinada dado que, a través del mundo virtual, se nutrió de distintos postulados ultraderechistas. Cult, por otro lado, nos apercibe sobre la facilidad que existe a la hora de crear un movimiento social en torno a la figura permeable de un líder que sabe como adoptar posturas populistas para emitir un mensaje que cala sobre una ciudadanía desinformada, desilusionada con las coyunturas socio-políticas del momento y/o polarizada por la crispación política, así como por la radicalización que irradian las redes sociales.

Este ensayo, por otro lado, demuestra que la tesis de Ferro que expusimos en la introducción es acertada pues, aun tratándose de una ficción serializada, Cult nos arroja luz sobre un testimonio valioso que presenta una realidad social que no incurre en tópicos, clichés, endulzamientos o demonizaciones innecesarias, tal y como hemos podido comprobar con las muestras de la bibliografía especializada que hemos cotejado.

\section{Referencias bibliográficas}

Allchorn, W. (2021). Tackling hate in the homeland: US Radical Right narratives and counternarratives at a time of renewed threat. https://t.co/mOMpA07myT

\footnotetext{
IICom (Instituto de Investigaciones en Comunicación) 
Alptraum, L. (2019). "Why Are The Proud Boys So Obsessed With Not Masturbating?". Gen medium.

https://gen.medium.com/why-are-the-proud-boys-so-obsessed-with-masturbationc9932364ebe2

Arias Gil, E.(2021). Aceleracionismo y extrema derecha ¿Hacia una nueva oleada terrorista?. Editorial Círculo Rojo.

Yves Camus, J. y Lebourg, N. (2020). Las extremas derechas en Europa: Nacionalismo, populismo y xenofobia. Clave intelectual.

Chip, B. y Lyon, M.N. (2000). Right-Wing Populism in America: Too Close for Comfort. New York: The Guilford Press.

Cornell, S. (2006). A well-regulated militia: the founding fathers and the origins of gun control in America. Oxford University Press.

Eatwell, R. y Goodwin, M. (2019). Nacionalpopulismo Por qué está triunfando y de qué forma es un reto para la democracia. Editorial Península.

Isenberg, N. (2017). White trash. The 400-Year Untold History of Class in America. Atlantic Book, (Kindle).

FBI.(1965). Subject: American Nazi-party monograph.

https://vault.fbi.gov/American\%20Nazi\%20Party\%20/American\%20Nazi\%20Party\%20Part\%201 \%20of\%202/view

_.(2019). Anti-Government, Identity Based, and Fringe Political Conspiracy Theories Very Likely Motivate Some Domestic Extremist to Commit Criminal, Sometimes, Violent Activity. Intelligence Bulletin, 1(15).

https://www.justsecurity.org/wp-content/uploads/2019/08/420379775-fbi-conspiracy-theoriesdomestic-extremism.pdf 
Ferro, M. (1977). Cine e historia. Barcelona: Editorial Gustavo Gili.

Kenton, L.(2019). "'This attack is a response to the Hispanic invasion of Texas': El Paso Walmart shooter Patrick Crusius, 21, posted twisted anti-Mexican manifesto online 20 minutes before storming store with an AK-47, shooting dead 20 people and wounding 26". Mail online. https://www.dailymail.co.uk/news/article-7319085/El-Paso-shooter-Patrick-Crusius-21-postedanti-Mexican-manifesto-online-20-minutes-shooting.html

Guerras Posmodernas. (2020). "Guerracivilismo en EE.UU.: The Boogaloo". https://guerrasposmodernas.com/2020/06/04/guerracivilismo-en-ee-uu-the-boogaloo/

Jäger et ali. (2021). Fashwave. Rechtsextremer Hass in Retro-Optik. Berlin: de:hate report https://t.co/2Wk0EZznBc

Mahdawi, A.(2017). "The troubling ascent of the LGBT right wing". The Guardian. https://www.theguardian.com/commentisfree/2017/oct/26/ascent-lgbt-right-wing-afd Mathis-Lilley, B. (2016). "Trump Was Recorded in 2005 Bragging About Grabbing Women "by the Pussy"'. The Slatest.

http://www.slate.com/blogs/the slatest/2016/10/07/donald trump 2005 tape i grab women b $\mathrm{y}$ the pussy.htm

Marantz, A. (2020). Antisocial. La extrema derecha y la 'libertad de expresión' en Internet. Madrid: Capitán Swing.

McKelvey, T. (2019). "What happened to Trump's promise on gun control?. BBC News. https://www.bbc.com/news/world-us-canada-50338937

Minna Stern, A. (2019). Proud boys and the white ethnoestate: How the alt-right is warping the American imagination. Beacon Press.

Mudde, C. (2007). Populist radical right parties in Europe. University Press. 
_. (2020). Ultradreta: Decàleg per entendre d'on ve i on va l'onada que amenaça la democracia. Barcelona: Edicions Saldonar (Kindle).

Mulloy, D.(2008). American Extremism: History, Politics and the Militia Movement. London: Routledge.

Nagle, A.(2018). Muerte a los normies: Las guerras culturales en internet que han dado lugar al ascenso de trump y la alt-right. Orcyni Press,

Peytibi, X. y Pérez-Diáñez, S. (2020). Cómo comunica la alt-right. De la rana Pepe al virus chino. Barcelona: Ediciones Beers\&Politics (Kindle).

Pollard, J. (2016). "Skinhead culture: the ideologies, mythologies, religions and conspiracy theories of racist skinheads". Patterns of Prejudice 50 (4-5),398-419.

Rodgers, L. y Bailey, D. (2020). "Trump wall: How much has he actually built?". BBC News. https://www.bbc.com/news/world-us-canada-46824649

Sanromán, D. L. (2008). La nueva derecha: cuarenta años de agitación metapolítica. Volumen 264. Centro de Investigaciones Sociológicas.

Thomas, E. (2021). Boogaloo Bois: the birth of a 'movement', from memes to real-world violence. The Strategies. https://www.aspistrategist.org.au/boogaloo-bois-the-birth-of-amovement-from-memes-to-real-world-violence/

Wang, Z. (2021). From Crisis to Nationalism? The Conditioned Effects of the COVID-19 Crisis on Neo-nationalism in Europe. Chinese Political Science Review (1)6, -20.

\section{Notas}

(1) "Que te jodan, mundo".

(2) Mandwich es la marca de una salsa que se vende en Estados Unidos, pero en la entrega tiene una connotación distinta. Esta contracción de las palabras anglosajonas, man, "hombre", y sandwich, "emparedado", es una alegoría a la supremacía masculina.

(3) Involuntary cebibate o "célibe involuntario". 
(4) "Hombres que siguen su propio camino" que evitan la compañía femenina, ya sea en términos afectivos o sexuales.

(5) "Artista de Ligue" cuyos integrantes, hombres, realizan acoso callejero a mujeres.

(6) Esta fue divulgada por el francés Renaud Camus que auguraba que la población blanca, católica y cristiana europea sería reemplazada por la inmigración árabe, bereber y/o iberoamericana.

(7) "Agarradlas por el coño". 